\title{
Produção e Degradação In Vitro de Estruturas Tubulares de Celulose Bacteriana
}

\author{
Vanessa A. Oliveira \\ Programa de Pós-Graduação em Engenharia Química, UFSC \\ Carlos Renato Rambo \\ Departamento de Engenharia Elétrica, UFSC \\ Luismar M. Porto \\ Departamento de Engenharia Química, UFSC
}

\begin{abstract}
Resumo: A necessidade de novos recursos em cardiologia tem direcionado a Engenharia de Tecidos ao desenvolvimento de vasos sanguíneos artificiais que atendam aos requisitos do organismo. Neste trabalho, estruturas tubulares de celulose bacteriana (CB) foram produzidas e sua degradação in vitro foi avaliada. Através de microscopia eletrônica de varredura constatou-se que não houve alterações significativas na microestrutura e morfologia das fibras de CB após ensaios de degradação. Os ensaios de degradação em soluções fisiológicas PBS e salina revelaram uma degradação substancialmente baixa após 20 semanas. A baixa velocidade de degradação dos vasos é de grande importância, visto que o processo para a formação de novos vasos (angiogênese) demanda tempo.
\end{abstract}

Palavras-chave: Celulose bacteriana, biodegradação, vasos sanguíneos artificiais.

\section{Production and In Vitro Degradation of Bacterial Cellulose Tubular Structures}

Abstract: The need of new techniques in cardiology has driven Tissue Engineering towards the development of artificial blood vessels that fulfill the requirements of the organism. In this work bacterial cellulose (BC) tubular structures were produced and their degradation in vitro was evaluated. No significant changes in microstructure and $\mathrm{BC}$ fiber morphology were observed by scanning electron microscopy after degradation tests. Degradation tests in physiological solutions (PBS and saline) revealed a very low degradation after 20 weeks. A low degradation rate of artificial vessels is important, since the process of new blood vessel formation (angiogenesis) demands time.

Keywords: Bacterial cellulose, in vitro degradation, artificial vessels.

\section{Introdução}

Mundialmente, as doenças cardíacas estão entre as maiores causas de mortes por ano. Patologias como aterosclerose, aneurisma e varizes levam milhares de pacientes a fazer procedimentos de substituição de vasos sanguíneos danificados. Essa intervenção é necessária para a manutenção da vida através do restabelecimento do fluxo sanguíneo ininterrupto, responsável pelo transporte e distribuição de fatores essenciais ao metabolismo tecidual ${ }^{[1]}$. Devido a esses altos índices de mortalidade por doenças cardíacas, diversos estudos em Engenharia de Tecidos visam o desenvolvimento de vasos artificiais ${ }^{[1-4]}$ para a substituição de vasos sanguíneos, o que evitaria a necessidade de se retirar segmentos de vasos de outras áreas do corpo do paciente para essa substituição, como ocorre em cirurgias de revascularização miocárdica por ponte de safena aortocoronária, onde parte da veia safena é retirada para fazer o desvio (bypass) de sangue da aorta para as artérias coronárias com problemas de fluxo, restabelecendo assim a irrigação sanguínea local ${ }^{[1]}$.

A celulose bacteriana (CB) tem se mostrado um biomaterial de grande potencial para uso em medicina regenerativa e outras aplicações em engenharia tecidual. As aplicações nessas áreas se devem às suas características e propriedades, como alta cristalinidade, quiralidade, resistência mecânica, porosidade, biocompatibilidade, atoxicidade e biodegradabilidade. Por essas propriedades, a CB está sendo utilizada em pesquisas de regeneração de cartilagens, vasos artificiais e em engenharia de tecidos ósseos ${ }^{[5-15]}$. Alguns pesquisadores utilizaram a celulose bacteriana como biomaterial base na construção de vasos sanguíneos artificiais ${ }^{[1-4]}$. Entretanto, qualquer biomaterial a ser implantado para testes in vivo deve ter sua origem e composição conhecidas para se evitar danos ao organismo ${ }^{[16,17]}$. Para esse fim foram realizados estudos da CB, como caracterização físico-química e biocompatibilidade com tecidos vivos e in vitro ${ }^{[15,18]}$.

Além da caracterização de um biomaterial com potencial para implante, é importante que sejam também conhecidos seu tempo de degradação, os produtos da degradação e os efeitos desses no organismo ${ }^{[5,19]}$. O estudo da degradação de tubos de celulose bacteriana é, portanto, o objetivo desse trabalho.

\section{Experimental}

A celulose utilizada nesse estudo foi sintetizada pela bactéria Gluconacetobacter hansenii, linhagem ATCC 23769, da "Coleção de Cultura Tropical (CCT) (Fundação André Tosello - Brasil) em meio de cultura 
estéril específico para a produção de celulose contendo $25 \mathrm{~g}$ de manitol, $5 \mathrm{~g}$ de extrato de levedura e $3 \mathrm{~g}$ peptona em 1 litro de água destilada.

Para a biossíntese de celulose bacteriana foram seguidos os métodos já desenvolvidos por Rambo et al. e Recouvreux et al. ${ }^{[20,21]}$, que consistem basicamente da inoculação de bactérias em um volume de $10 \%$ em relação ao volume do meio de cultura; crescimento estático e à temperatura ambiente $\left(25^{\circ} \mathrm{C}\right)$ em um período de 7 dias.

Para a obtenção de tubos cilíndricos de celulose bacteriana (vasos de CB) construiu-se um aparato em silicone, como mostrado na Figura 1. Nesse aparato introduziu-se o meio de cultura inoculado com a bactéria numa razão de $10 \%$ em volume para incubação por 7 dias em crescimento estático. Foram obtidos tubos de celulose bacteriana de $15 \mathrm{~cm}$ de comprimento por $12 \mathrm{~mm}$ de diâmetro interno e $1 \mathrm{~mm}$ de espessura de parede. Os vasos de CB foram então lavados em água destilada e purificados em solução aquosa de hidróxido de sódio a $0,1 \mathrm{M}$ e $0,5 \mathrm{M}$ em banho-maria a $90{ }^{\circ} \mathrm{C}$ durante 1 hora. A caracterização estrutural dos vasos foi feita através
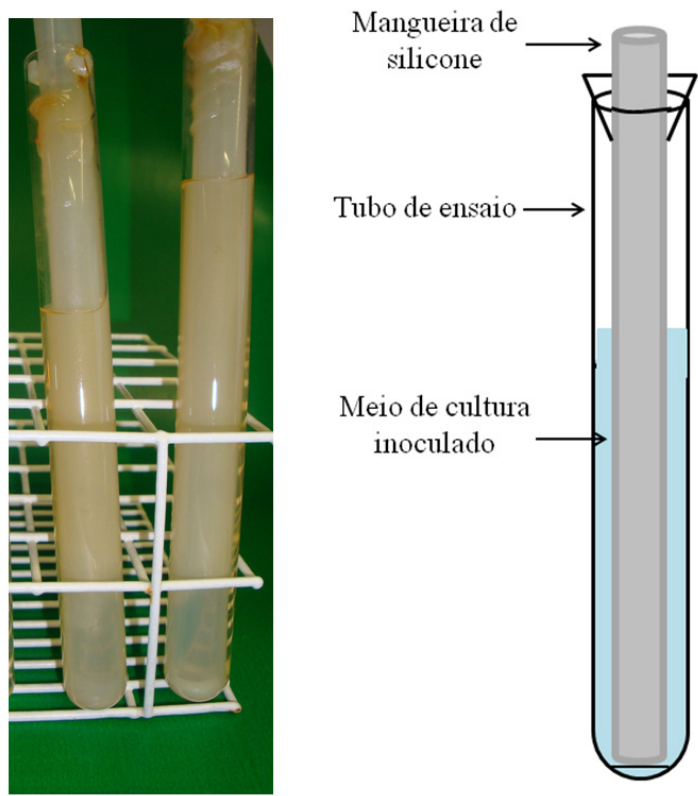

Figura 1. Aparato para a produção estática de vasos.
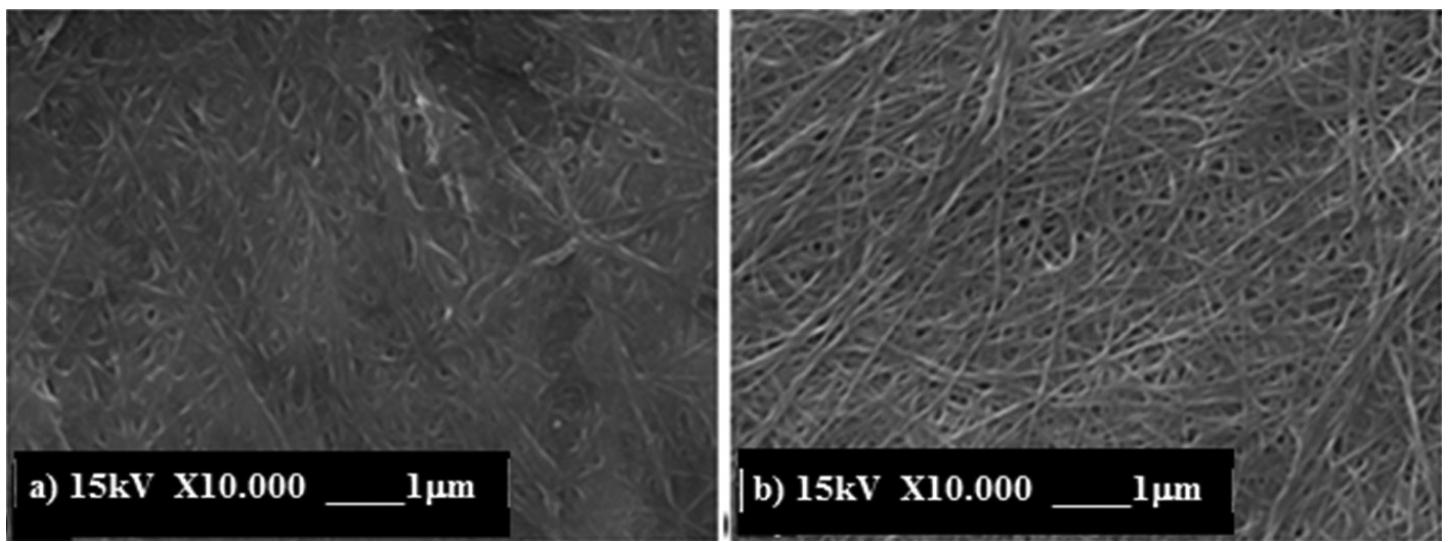

Figura 2. Membranas de $\mathrm{CB}$ tratadas em $\mathrm{NaOH} 0,1 \mathrm{M}$ (a) e $0,5 \mathrm{M}$ (b). de Microscopia Eletrônica de Varredura, MEV, (JEOL, JSM- 6390LV) em $15 \mathrm{kV}$. Para a análise em MEV as amostras foram secas em estufa a $50{ }^{\circ} \mathrm{C}$ durante 24 horas, depois fixadas com fita de carbono sobre suportes de $\mathrm{Al} \mathrm{e}$ recobertas com ouro.

Para os ensaios de degradação dos vasos de $\mathrm{CB}$, os vasos tratados em $\mathrm{NaOH} 0,1 \mathrm{M} \mathrm{e} 0,5 \mathrm{M}$ foram segmentados em anéis de $3 \mathrm{~cm}$ de comprimento, $12 \mathrm{~mm}$ de diâmetro interno e 0,5 $\mathrm{mm}$ de espessura de parede. Esses segmentos foram colocados em soluções de PBS (Phosphate Buffered Saline) - Solução Salina Tamponada com Fosfato e Salina ( $\mathrm{NaCl}$ 0,9\%), autoclavados e deixados em incubadora a $37,8{ }^{\circ} \mathrm{C}$. Os ensaios de degradação dos vasos seguiram um protocolo de 20 semanas em que nos tempos de $0,4,8,12,16$ e 20 semanas foram realizadas as dosagens dos níveis de glicose através de espectrofotometria UV-Vis (Shimadzu, UV Mini 1240). A concentração de glicose nas amostras foi determinada através do teste enzimático colorimétrico para dosagem da glicose em fluídos orgânicos da Bioliquid (Laborclin PR), utilizando comprimento de onda de $505 \mathrm{~nm}$.

\section{Resultados e Discussão}

Após tratamento com o hidróxido de sódio houve uma separação das fibras (Figura 2) devido aos íons $\mathrm{Na}^{+}$ e eventuais sais presentes nos interstícios interfiblilares. George e colaboradores ${ }^{[18]}$ relataram que em meio alcalino ocorre uma quebra do padrão de ligação de hidrogênio das microfibrilas de celulose. Quanto maior a concentração da solução de $\mathrm{NaOH}$ utilizada, maior o número de íons sódio que penetrarão na membrana, quebrando ligações de hidrogênio inter e intra moleculares entre as fibras de celulose adjacentes e, consequentemente, mais "afrouxado" ficará o arranjo estrutural da celulose, resultando em um inchamento da película ${ }^{[16,18,22]}$.

A aparência dos vasos de celulose bacteriana após purificação é de hidrogéis translúcidos (Figura 3). O diâmetro interno do vaso é controlado, de acordo com o diâmetro externo da mangueira de silicone que se utilizar. O silicone é o material de escolha por suportar a temperatura de autoclavagem $\left(121^{\circ} \mathrm{C}\right)$ e por apresentar certa porosidade que impede a migração de bactérias, mas permite a difusão de oxigênio. 
A Figura 3 apresenta fotografias que mostram o aspecto dos tubos produzidos após secagem. Observa-se que a estrutura tubular se mantém praticamente inalterada após secagem. Os vasos foram analisados em MEV em cortes longitudinais das paredes internas e externas. A formação dos tubos ocorre de forma radial, de forma que as bactérias depositam a celulose na parede externa do tubo interno de silicone formando camadas, como se observa no corte longitudinal da parte interna do vaso (Figura 4). Já no corte da parte externa a aparência é mais uniforme, porém com menor densidade de fibras que a interna. Outra análise foi feita em corte diagonal ao vaso de CB com o intuito de observar a rede de fibras partindose da parte interna até a externa da espessura do vaso (Figura 4c).

O substituto ideal de um vaso sanguíneo deve promover a endotelização e servir de matriz para a formação de um novo vaso. Os vasos de CB apresentam boas características cirúrgicas como o manuseio e sutura do biomaterial e o restabelecimento imediato do fluxo sanguíneo após a completa anastomose ${ }^{[3]}$. Estudos de substituição da artéria carótidas de porcos por vasos de CB mostrou que não houve dilatação, abertura da sutura ou formação de aneurismas, além do vaso artificial não sofrer alterações significativas no seu diâmetro após 90 dias do implante ${ }^{[3]}$. O mesmo estudo ainda mostra que os vasos artificiais permitiram a endotelização e formação de tecido tri-laminar com estrutura semelhante à da carótida normal, fato este que demonstra que o implante de células ou fatores de crescimento na matriz é dispensável, tornando o procedimento mais prático.

Nos ensaios de degradação dos tubos de celulose, a análise das amostras em Espectrofotometria de UV-VIS para glicose foi comparada com os controles compostos de $20 \mathrm{~mL}$ de reagente de cor mais $20 \mu \mathrm{L}$ de PBS ou Salina. A Figura 5 apresenta a concentração de glicose a)

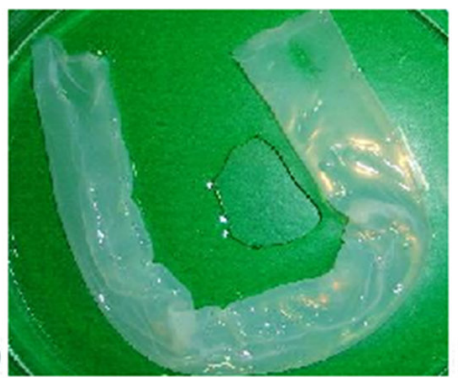

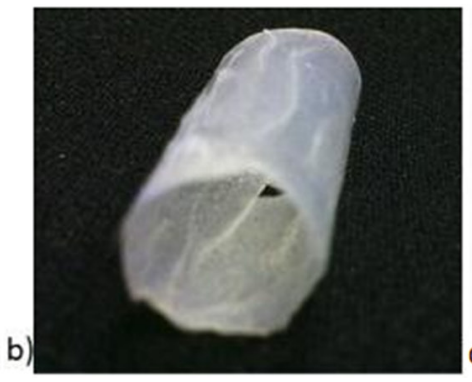

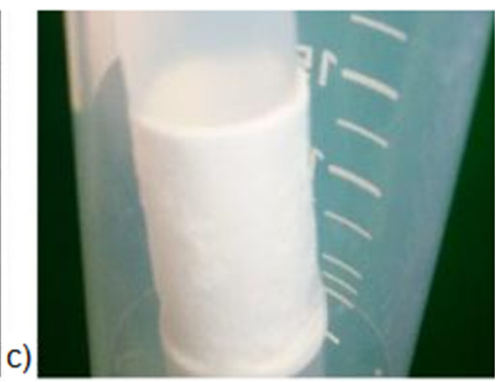

Figura 3. Vaso de Celulose Bacteriana: a) vaso hidratado; b) vaso seco em estufa a $50{ }^{\circ} \mathrm{C}$ por 24 horas; e c) vasos liofilizados.
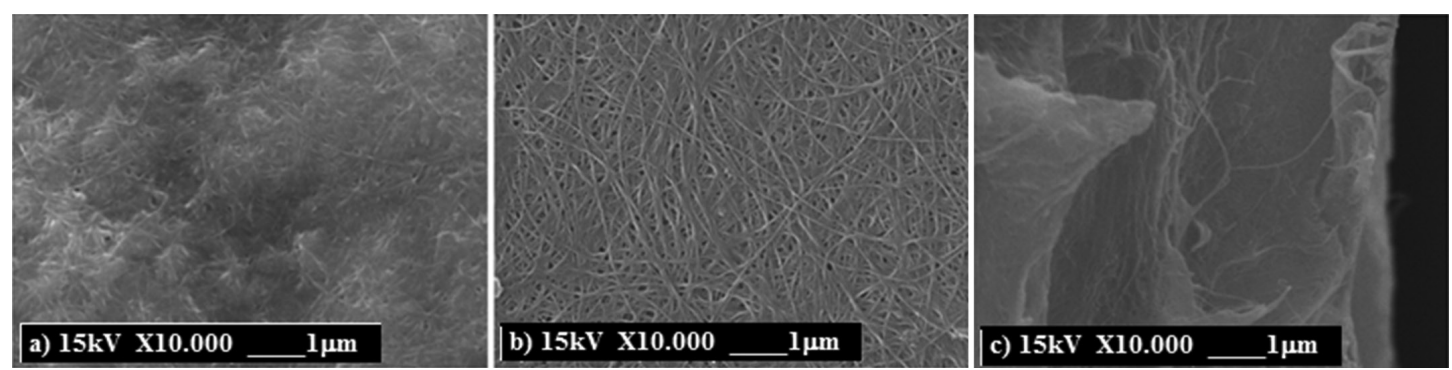

Figura 4. Micrografia de MEV de um vaso de CB mostrando: (a) lado interno com aspecto mais condensado, apresentando grumos; (b) lado externo (menos denso); (c) Corte em diagonal, com início na parede interna até a parede externa evidenciando as camadas.
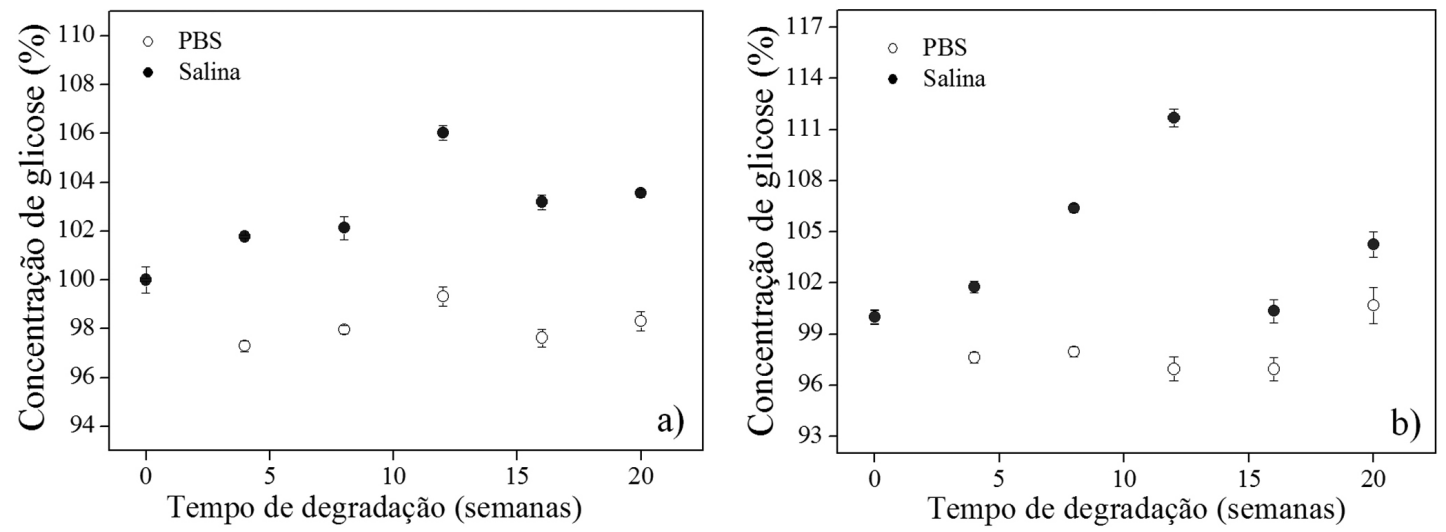

Figura 5. Degradação dos vasos previamente mercerizados em $\mathrm{NaOH} 0,1 \mathrm{M}$ (a) e $\mathrm{NaOH}$ 0,5 M (b) ao longo das 20 semanas: os valores correspondentes à semana $0(100 \%)$ representam os controles para análise de Espectrofotometria de UV-VIS: 2,95 é a concentração obtida pela absorbância do reagente de cor $+20 \mu 1$ de PBS e o 2,82 é a do reagente de cor + salina. 

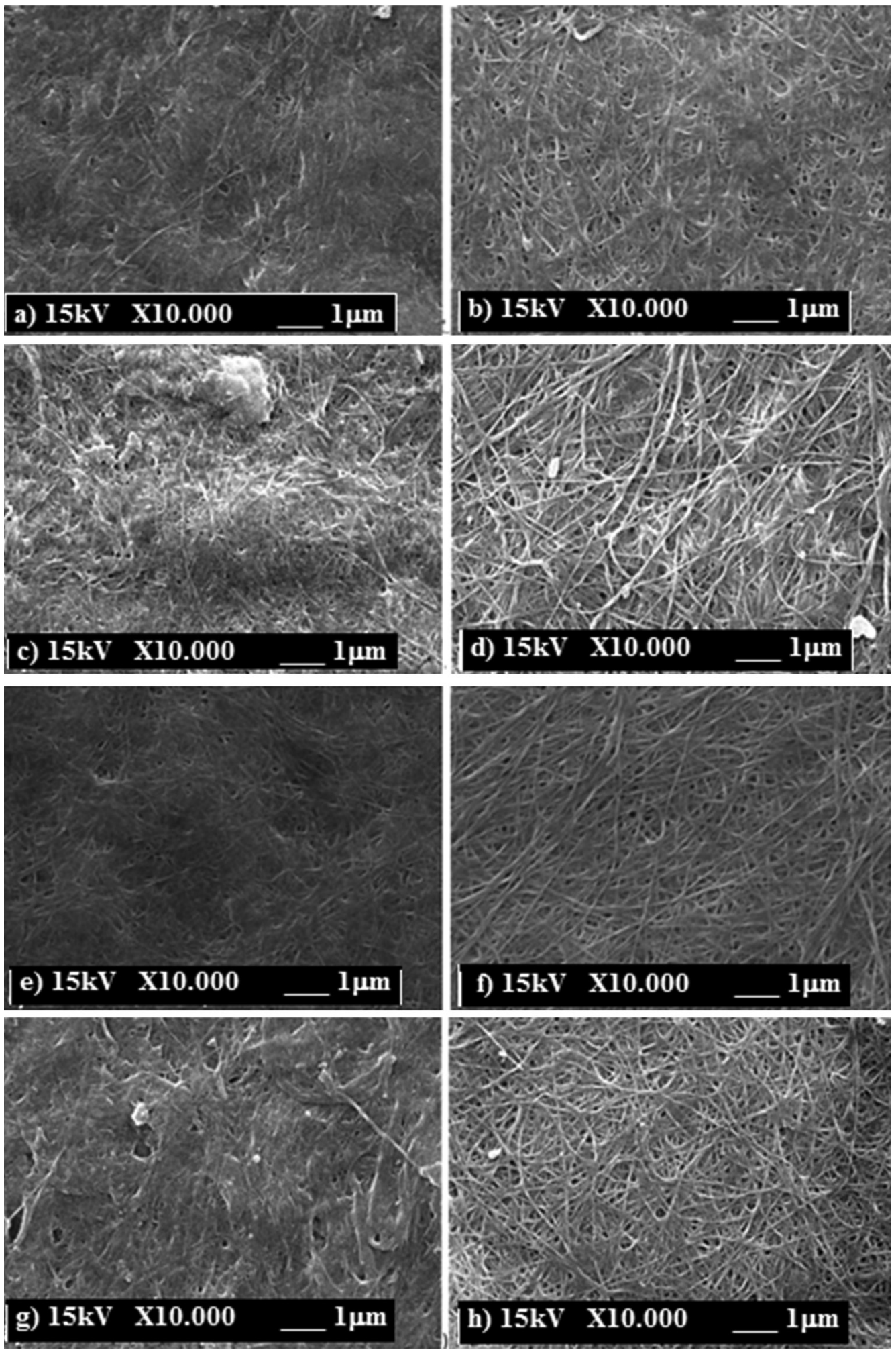

Figura 6. Micrografias de MEV dos ensaios de degradação dos vasos: de modo geral observa-se que o lado interno dos vasos (figuras da coluna esquerda) estão mais densos e compactos que o lado externo destes (figuras da coluna direita). Quanto à degradação: (a) e (b) foram tratados em $\mathrm{NaOH}$ 0,1M e imersos em PBS no período de 4-20 semanas não apresentando alterações estruturais que indiquem degradação dos vasos; (c) e (d) foram tratados em NaOH 0,1 M e imerso em Salina durante o período de 4-20 semanas, não apresentando degradação, mas precipitação de sais de sódios (d); (e) e (f) foram tratados em $\mathrm{NaOH}$ 0,5M imersos em PBS durante o período de 4-20 semanas; (g) e (h) foram tratados em NaOH 0,5 M e imersos em Salina no período de 4-20 semanas não apresentando degradação aparente, mas precipitação de sais de sódio. 
(mg/dL) em função do período de tempo de degradação. Os controles apresentaram absorbâncias que convertidas resultaram nos valores de $2,95 \mathrm{mg} / \mathrm{dL}$ para o controle de PBS e $2,82 \mathrm{mg} / \mathrm{dL}$ para o controle de salina e por isso foram utilizados como padrão para as concentrações de glicose, onde valores inferiores a eles são considerados ausência de glicose e valores maiores indicam a presença desse monossacarídeo. Todas as amostras com PBS - com exceção da amostra da $20^{\mathrm{a}}$ semana que foi previamente tratada com $\mathrm{NaOH} 0,5 \mathrm{M}$ apresentaram valores inferiores ao padrão indicativos de ausência de glicose. Em contrapartida todas as amostras com salina, exceto a da $16^{\mathrm{a}}$ semana tratada com $\mathrm{NaOH}$ à $0,5 \mathrm{M}$, resultaram em valores superiores ao controle tendo seu maior pico, em ambos tratamentos, na $12^{\mathrm{a}}$ semana. No entanto os valores superiores estavam muito próximos do padrão, indicando baixo grau de degradação.

Para implantes in vivo o biomaterial deve ser totalmente degradável ${ }^{[3]}$ não permanecendo tempo desnecessário no organismo. Porém é de grande importância conhecer seu tempo de degradação e avaliar se é inferior, ideal ou superior ao proposto a sua função ${ }^{[5]}$. Em regeneração tecidual não é interessante que a matriz se degrade em tempo inferior ao da formação do novo tecido, e sim que seja substituída gradativamente. Isso é desejado no implante dos vasos de $\mathrm{CB}$ onde uma degradação rápida do biomaterial antes do restabelecimento do novo vaso comprometeria o fluxo sanguíneo e promoveria extravasamento de células para o meio externo aos vasos com possíveis complicações patológicas. Segundo a literatura o maior problema está em sincronizar a degradação do biopolímero com o crescimento das células para criar o material com degradação programada ${ }^{[3]}$.

A Figura 6 apresenta micrografias de MEV das amostras após os ensaios de degradação. Observa-se que não houve degradação aparente em nenhum grupo de amostras, não havendo nenhuma alteração estrutural. Entretanto, houve a presença de precipitados de sais de sódio nas amostras imersas em Salina. Por outro lado, a mesma figura corrobora $o$ fato da parede interna dos tubos de celulose bacteriana possuir uma densidade maior de fibras, conferindo um aspecto muito mais compacto internamente, em relação à parede externa do tubo, que se apresenta com uma rede de fibras mais frouxa e em menor quantidade $^{[3]}$. Essa maior densidade no lúmen do tubo é de extrema valia para aplicação da CB como substituto de vasos sanguíneos, uma vez que no interior do tubo irá circular plasma e células sanguíneas, que não podem atravessar para o meio externo do vaso. Deve-se salientar que este é um trabalho preliminar, que mostra apenas uma faceta da extensa gama de propriedades da celulose bacteriana. Desta forma, procurou-se apenas avaliar, de maneira sistemática, a habilidade de manutenção da integridade química da celulose, para que possa ser usada como material suporte para regeneração tecidual de vasos sanguíneos.

\section{Conclusões}

Por meio dos resultados deste trabalho pode-se constatar que os tubos de celulose bacteriana apresentaram uma degradação muito lenta, confirmado por ensaios conduzidos durante 20 semanas. A baixa velocidade de degradação dos vasos é de grande importância, visto que o processo para o estabelecimento de novos vasos (angiogênese) demanda tempo. Além disso, uma lenta degradação é interessante quando não se deseja que o implante celulósico se degrade rapidamente, permanecendo inalterado estruturalmente por muitos meses no organismo, como ocorre com os stents na aterosclerose. De modo geral os ensaios de degradação simularam condições de um organismo vivo. Os vasos desenvolvidos apresentam potencial para a utilização como suporte temporário para regeneração de vasos sanguíneos, sendo necessários ensaios in vivo para a efetiva validação da CB como vaso sanguíneo artificial.

\section{Agradecimentos}

Ao Conselho Nacional de Desenvolvimento Científico e Tecnológico (CNPq) pelo apoio financeiro. Ao Laboratório de Simulação Numérica de Sistemas Químicos (LABSIN) e ao Laboratório de Transferência de Massa (LABMASSA). Ao Laboratório Central de Microscopia da UFSC (LCME) pela obtenção dos MEVs apresentados neste trabalho.

\section{Referências Bibliográficas}

1. World Health Organization - WHO. - "Cardiovascular diseases (CVDs)", in: Factsheet $\mathrm{n}^{\circ}$ 317, Jan (2011). Disponível em: <http://www.who.int/>. Acesso em: 20 fev. 2012

2. Klemm, D.; Schumann, D.; Udhardt, U. \& Marsch, S. - Prog. Polym. Sci., 26, p.1561 (2001). http://dx.doi. org/10.1016/S0079-6700(01)00021-1

3. Wippermann, J.; Schumann, D.; Klemm, D., Kosmehk, H.; Saleni-Gelani, S. \& Wahlers, T. - Eur. J. Vasc. Endovasc. Surg., 37, p.592 (2009). http://dx.doi.org/10.1016/j. ejvs.2009.01.007

4. Fink, H. - "Artificial blood vessels: Studies on endothelial cell and blood interactions with bacterial cellulose", Doctoral Thesis, University of Gothenburg, Sweden (2009).

5. Chen, Y. M.; Xi, T.; Zheng, Y.; Guo, T.; Hou, J.; Wan, Y. \& Gao, C. - J. Bioac. Compat. Pol., 24, p.137 (2009). http:// dx.doi.org/10.1177/0883911509102710

6. Klemm, D.; Heublein, B.; Fink, H. \& Bohn, A. - Angew. Chem. Int., 44, p.3358 (2005). http://dx.doi.org/10.1002/ anie. 200460587

7. Svensson, A.; Nicklasson, E.; Harrah, T.; Panilaitis, B.; Kaplan, D.L.; Brittberg, M. \& Gatenholm - Biomaterials, 4, p.419 (2005).

8. Oprea, A.; Neamtu, A.; Stoica, B. \& Vasile, C. - "Cellulose/ chondroitin sulphate hydrogels as carriers for drug delivery applications", in: Analele Stiintifice ale Universitatea Alexandru Ioan Cuza, Sectiunea Genetica si Biologie Moleculara, TOM X, Iasi-Romênia (2009).

9. Remunan-Lopes, C.; Lorenzo-Lamosa, M. L.; Vila-Jato, J. L. \& Alonso, M. J. - Eur. J. Pharm. Biopharm., 45, p.49 (1998).

10. Sabnis, S. \& Block, L. H. - Int. J. Biol. Macromol., 27, p.181 (2000). http://dx.doi.org/10.1016/S0141-8130(00)00118-5 
11. Moosavi-Nasab, M. \& Yousefi, A. R. - World Academy of Science, Engineering and Technology, 68, p.1248 (2010).

12. Fontana, J. D.; Desouza, A. M.; Fontana, C. K.; Torriani, I. L.; Moreschi, J. C.; Gallotti, B. J.; Desouza, S. J.; Narcisco, G. P.; Bichara, J. A. \& Farah, L. F. X. - Appl. Biochem. Biotech., 24-25, p.253 (1990). http://dx.doi.org/10.1007/ BF02920250

13. Kacuráková, M.; Smith, A. C.; Gidley, M. J. \& Wilson, R. H. - Carbohyd. Res., 337, p.1145 (2002).

14. Backdahl, H.; Helenius, G.; Bodin, A.; Nannmark, U.; Johansson, B.R.; Risberg, B. \& Gatenholm, P. - Biomaterials, 9, p.2141 (2006).

15. Helenius, G.; Bäckdahl, H.; Bodin, A.; Nannmark, K. U.; Gatenholm, P. \& Risberg, B. - J. Biomed. Mat. Res. Part. A, 76A, p.431 (2005). http://dx.doi.org/10.1002/ jbm.a.30570

16. Watanabe, K.; Eto, Y.; Takano, S.; Nakamori, S.; Shibai, H. \& Yamanak, S. - Cytotechnology, 13, p.107 (1993). http:// dx.doi.org/10.1007/BF00749937

17. Pereira, A. P. V.; Vasconcelos, W. L. \& Oréfice, R. L. - Polimeros, 9, p.104 (1999). http://dx.doi.org/10.1590/ S0104-14281999000400018
18. George, J.; Ramana, K. V.; Sabapathy, S. N.; Jagannath, J. H. \& Bawa, A. S. - Int. J. Biol. Macromol., 37, p.189 (2005). http://dx.doi.org/10.1016/j.ijbiomac.2005.10.007

19. Oliveira, A. F.; Cristiano, C. M. Z.; Andreani, L.; Porto, L. C. \& Soldi, V. - "Estudos cinéticos de degradação térmica de blendas formadas por carboximetilcelulose/goma guar ou hidroxipropilmetilcelulose", in: Anais $17^{\circ}$ Congresso Brasileiro de Engenharia e Ciência dos Materiais, Foz do Iguaçu-PR, nov (2006).

20. Rambo, C. R.; Recouvreux, D. O. S.; Carminatti, C. A.; Pitlovanciv, A. K.; Antônio, R. V. \& Porto, L. M. - Mat. Sci. Eng. C, 28, p.549 (2008). http://dx.doi.org/10.1016/j. msec.2007.11.011

21. Recouvreux, D. O. S.; Rambo, C. R.; Berti, F. V.; Carminatti, C. A.; Antônio, R. V.; \& Porto, L. M. - Mat. Sci. Eng. C, 31, p.151 (2011). http://dx.doi.org/10.1016/j. msec.2010.08.004

22. McKenna, B. A.; Mikkelsen, D.; Wehr, J. B.; Gidley, M. J. \& Menzies, N. W. - Cellulose, 16, p.1047 (2009). http:// dx.doi.org/10.1007/s10570-009-9340-y

Enviado: 08/01/12 Reenviado: $16 / 09 / 12$ Aceito: 05/10/12 